\title{
Susceptibility to empathy and its relationship to emotional maturity among university students (An applied study on students of the college of education, university of Diyala, Iraq, 2020 AD)
}

\section{Ghassan Ghazanfar Hamid ${ }^{1}$, Maki Babiker Saeed Dewa², Al-Fatih Mustafa Suleiman Al-Kanani ${ }^{3}$}

\footnotetext{
${ }^{1}$ Researcher and PhD student, Department of Applied Psychology, College of Education, University of Gezira, Sudan

${ }^{2}$ Associate Professor of Educational Psychology, College of Education, University of Gezira, Sudan

${ }^{3}$ Associate Professor of Educational Psychology, College of Education, University of Gezira, Sudan

2makkideiwa@gmail.com
} 


\section{Susceptibility to empathy and its relationship to emotional maturity among university students (An applied study on students of the college of education, university of Diyala, Iraq, 2020 AD)}

\section{Ghassan Ghazanfar Hamid ${ }^{1}$, Maki Babiker Saeed Dewa ${ }^{{ }^{2}}$, Al-Fatih Mustafa Suleiman Al-Kanani ${ }^{3}$}

${ }^{1}$ Researcher and PhD student, Department of Applied Psychology, College of Education, University of Gezira, Sudan

${ }^{2}$ Associate Professor of Educational Psychology, College of Education, University of Gezira, Sudan

${ }^{3}$ Associate Professor of Educational Psychology, College of Education, University of Gezira, Sudan

²makkideiwa@gmail.com

Received: $3^{\text {rd }}$ April 2021 Revised: 30 $30^{\text {th }}$ May 2021 Accepted: 19 $9^{\text {th }}$ June 2021 DOI: https://doi.org/10.31559/CCSE2021.2.2.1

Abstract: The capacity for empathy represents an emotional experience that affects human life in facing problems and difficulties and providing assistance to those we feel that needs it, and in fact it represents an essential component of human life, in addition to its impact on their psychological health. The present study aimed to uncover the relationship between the capacity for empathy and emotional maturity among university students, and in order to achieve the objectives of the current study, the researcher built a scale of sympathy capacity according to according to the researcher also built the scale of emotional maturity according to the definition of (CATEL), and the researcher verified One of the psychometric characteristics of the two study scales, and the basic study sample reached (400) students from Diyala University for the morning study, for the academic year (2019-2020), and they were selected according to the random stratified method of equal distribution, and the data were processed statistically using the package program Statisticians for Social Sciences (SPSS). Several results were reached, including: Among them: There is a tendency of sympathy among the individuals of the study sample that is statistically significant in favor of university students. There are statistically significant differences in the susceptibility of empathy according to the gender variable and in favor of females. The study recommends making use of the results of the current study by educational counselors. It also recommends that researchers in the field of psychology make use of the measure of the susceptibility of empathy in order to diagnose the susceptibility of empathy. The necessity of creating a positive academic environment for university students to help increase their self-confidence when they encounter problems. The study suggests conducting a number of researches on the variable susceptibility to empathy in daily life and society in order to identify its degree and the possibility of developing it in a way that serves societies.

Keywords: Maturity; Empathy; Emotional; Students.

${ }^{*}$ Corresponding author

Maki Babiker Saeed Dewa

Associate Professor of Educational Psychology, College of Education, University of Gezira, Sudan

E-mail:makkideiwa@gmail.com 
International Journal of Childhood, Counselling, \& Special Education (CCSE), Volume2, Issue2, June: 2021, pp.67-84

\section{Introduction}

The capacity for empathy represents an emotional experience that affects human life in facing problems and difficulties and helping those we feel that needs it. In fact, it represents an essential component of human life, in addition to its impact on their psychological health. (Expelled, 2018: 4).

The weakness in the capacity for empathy is mainly due to the result of the attention that the individual receives in childhood, as well as the cruelty of the parents, which does not help him to establish positive sympathy with the parents and then the peers and members of the community on the other side, which leads to a lack of understanding, dynamism and a lack of sense of security and attachment With others, which will ultimately be returned to the plunder and withdrawal from others, as the intimate relationships between family members and the concern of (parents) for their children and work to solve their problems and respect their opinions and feelings, children feel that their family is emotionally connected and a cohesive unit, as the awareness of family cohesion enables family members to Interest in others and makes them more connected and sympathetic to others. (Yunus, 2004, 74)

\section{Study Problem:}

It has been found that the weakness of sympathy with others are all cases that may result in behaviors and behaviors unacceptable by the individual in various situations, and in addition to that, many of the situations that face a person at the university level, whether in terms of quantity or type, give rise to many emotional states, especially after The circumstances and wars that the various countries were subjected to and still exist to this day have left a psychological impact on their health, which is represented in the weakness of emotional maturity. (AlMousawi, 2013: 2-4)

The researchers being their field of work mainly at the university level, they noticed this phenomenon widespread among college students, which based on knowing the opinion of other professors on this topic by doing an exploratory questionnaire found in Appendix No. (1) and distributing (20) forms to other professors to know their opinions about This topic and I got a percentage $(100 \%)$ that this problem is widespread among university students.

In addition to all that was mentioned, the following main question arose:

Do university students have a statistically significant ability to empathy?

From the main question, the following sub-questions are divided:

1. Are there statistically significant differences in the susceptibility of empathy among university students according to the gender variable (males - females?

2. Are university students characterized by emotional maturity?

3. Is there a statistically significant relationship between the variables of the susceptibility of empathy and 
International Journal of Childhood, Counselling, \& Special Education (CCSE), Volume2, Issue2, June: 2021, pp.67-84

$$
\begin{aligned}
& \text { emotional maturity among } \\
& \text { university students? }
\end{aligned}
$$

\section{Importance of studying:}

The importance of the study lies in the following:

\section{First: The Theoretical Importance:}

1. The current study is considered a pioneer in dealing with three variables, which are sympathy, emotional maturity, and selfconfidence. As there is no similar study - to the knowledge of the researchers - for these three variables together, despite the need for the country and some countries for this study because they are exposed to many negative phenomena that are (anxiety, fear, sympathy with others, providing them with assistance, undermining self-confidence, withdrawing and not facing problems.

2. The importance of the topic to which the present study leads is that emotional maturity and susceptibility to empathy are the result of common circumstances and events that a person is exposed to in the various stages of his development due to many external influences that may affect a direct effect depending on the age stage that affect the behavioral aspects Emotional, social and inability to interact with others.

\section{Second: Application Importance:}

1. The current study will provide three tools to measure the variables, which are (sympathy susceptibility and emotional maturity) for diagnosis and treatment, and in addition it will open the door to new research in the future, which will bring us new scientific benefits in these different fields.

2. The importance of the sample covered by the current study represented by university students and because they have a prominent and important role in society because they will be responsible for a segment of students during their work or application in schools.

\section{Objectives of the Study:}

This study seeks to achieve the following objectives:

1. Investigating the differences in the ability to empathize among university students according to the gender variable (male - female).

2. Trying to identify the relationship between the two variables of empathy and emotional maturity among university students.

3. Knowing the potential for the independent variable to contribute (the susceptibility of empathy to the dependent variable (emotional maturity) among university students.

\section{Study Hypotheses:}

This study seeks to verify the following hypotheses:

1. University students have a statistically significant capacity for empathy.

2. University students are characterized by emotional maturity.

3. There are no statistically significant differences in the susceptibility of empathy among university students according to the gender variable (male - female).

4. There is no statistically significant relationship between the variables of the susceptibility of empathy and 
International Journal of Childhood, Counselling, \& Special Education (CCSE), Volume2, Issue2, June: 2021, pp.67-84

emotional maturity among university students?

\section{The Limits of the Study:}

The current study is determined for students of Diyala University of the Ministry of Higher Education in Diyala Governorate for the academic year (2020_2021).

\section{Terminology of Study:}

\section{Susceptibility to Empathy:}

Diamond (Dymonid,

defined it: it represents an imaginary transformation or transfer of a person into the thoughts, feelings, and behavior of another person, and whoever perceives the world from the point of view of the other. Dymonid, 1949: p127)

\section{Emotional Maturity:}

Guilford (1959) defined it: It is the characteristic that is unique to the individual and has an objective view of himself and a sense of comfort in different situations and is far from the extremist vision, otherwise it will result in increased sensitivity when he sees others. (Guilford, 1959: p98)

\section{The University Stage:}

It is the stage that is after the secondary or preparatory stage, which includes the scientific and literary departments, and the period of study in it is from (4-6) years. (Beck, 2000, 13).

\section{Theoretical framework and previous studies}

\section{Introduction:}

The dictionaries have interpreted in the Arabic language that the capacity for sympathy represents the feeling of lips towards others, meaning it means sympathy for them, meaning compassion for him and sympathy for him, and from here we reach that the capacity for sympathy is a human condition (Ibn Manzur, B. An emotional response as a result of the individual's perception of other people's emotions through imagining himself in the place of the other (Mahmoud, 2004: 177-178)

\section{Concept of empathy:}

Kazdin (2000) pointed out that the ability to sympathize is an emotional and emotional response that focuses on the feelings and emotions of the other individual that may be represented by feelings of love and compassion. A number of factors may emerge as a result of the capacity for sympathy, the most important of which is taking the perspective of the other individual or retrieving memory information through understanding the emotional state. For the other person (Kazdin, 2000: p 528), and one of the most important functions of sympathy is that the individual, through the capacity for empathy, derives feelings of love, affection and goodness through it, as it makes a person in the eyes of others good and valid in the hearts of others, as it represents the integration factor of human beings in order to obtain For psychological comfort in mutual relationships with others. (Mahmoud, 2004: 178)

While Abraham mentioned that sympathy with others or presenting a capacity for empathy may be due to many moral actions and judgments, such as emotional anger described by Steward, a tendency that represents a natural reaction as a result of the judgment of reason and sympathy for 
International Journal of Childhood, Counselling, \& Special Education (CCSE), Volume2, Issue2, June: 2021, pp.67-84

those whose feelings have been hurt. People with sympathy are those who have moral values that are defined according to their needs. (Abraham, 1999: 211).

\section{Concept of Emotional maturity:}

Emotional maturity represents a state of psychological stability called psychoanalysts by the term emotional stability, where it was found that the person who controls his emotions is a person who has mental health or not and a mature emotional person and the expression is emotional according to what suits the situation because the most negative qualities we find in maturity Emotional due to the nature of their thinking and dealing with the situation. (Al-Bayoumi, 2019: 156)

(Chrystal, 2012) has indicated that emotionally immature people have few friends, and if they have friends, they form an image that represents themselves, unlike emotionally mature people. Emotionally mature people have positive qualities who have patience and optimism, unlike emotionally immature people who are frowned upon and envious. That is, they carry all the negative traits in their personality. (Dewa \& Buddy, 2019: 272)

The emotionally stable individual is a mature person from the emotional point of view, and he is the one who controls his self-control when he faces slight emotional tension and does not get angry or easily affected, and his feeling of self-confidence and gaining it through interaction with his environment and his dealings with others creates a sense of security for himself and others because if the individual learns to exchange love And loyalty in different stages of his life can communicate his feelings in the best possible way to others, as well as learn from him how to exchange that with him and how to curb his anger and tension, which made him play his social roles in all positive. (Rashid, 2017: 516)

Life, in its nature, is varied, not without emotions, and we cannot deny the existence of emotions, since if it is empty, we can consider it an abnormal life, and in light of this, the term emotional maturity does not mean a lack of emotion, as the emotionally mature individual is the one who can coexist with these emotions and keep them But reasonably so in order for him to keep his life going and achieve The same, but directs it to achieve its positive goals. (Al-Issawi, 2002: 427)

\section{Types of Factors Influenced by} Emotional Maturity:

Subjective factors specific to the individual: They range under the subjective factors and genetic factors, as well as some physiological and cognitive disorders.

1. Environmental factors: it includes the social and physical environment on which the problems, pressures, and the inability of the individual to achieve his goal occur.

It can be said that through these factors and the interaction between them, an emotional exudation takes place. (Mahmoud, 2020: 167).

Characteristics of a mature and emotional person: Emotionally mature individuals are characterized as calm and tolerant people who do not make mistakes and are satisfied with their 
share. They are also flexible, tolerant, harmonious and tolerate psychological pressures. As for individuals who are emotionally immature, they are moody and quick to anger and excitement when they are exposed to a situation or pressures or criticism and a lot of complaint, controversy, incompatible and psychologically incompatible. They are also aggressive, insecure, and low in self-esteem. (Cook, 2005: 15)

\section{Signs of an Emotionally Mature Person:}

1. The ability is an individual to love and be loved: it means an individual's ability to express feelings of love towards others without fear and tension when the individual feels safe and confident.

2. The ability of the individual to learn experiences: it means that the individual learns from his mistakes and is responsible for them as well as his self-criticism and works on a change for the better in order not to fall into the same mistake as the person does not blame himself, but tries to gain experiences through these mistakes that are Fall for her and learn from her.

3. The individual's ability to face reality without escaping from it: that is, the emotionally mature individual has to deal with his problem that he faces with confidence without escaping from it and developing the most appropriate solutions for it.

4. Taking care of self-giving and taking it: -As mature individuals take their needs for others when they feel safe. Where they are allowed to spend in terms of work and effort for the improvement of the life situation of the people they love while accepting the bids of others as balance and maturity one of them is related to the second (Jerome Murray, 2004: 11)

5. The ability of the individual to collaborate collectively: - As the emotionally mature individual possesses the trait of love for others, as well as he wants to innovate and add to this life, that is why we can expect him to succeed in work as work represents his social place that is indispensable for the sake of achieving his accomplishments.

6. Creativity: The emotionally mature individual feeling of love, safety and social harmony is directed to the path of creativity to have a vision of a positive life that makes him hear its secrets and reveal the relationships between mutual things, and thus we find the individual becomes creative with himself and his community, and creativity makes the mature individual emotionally glowing all the time.

7. The ability of the individual to get rid of symptoms of tension: - That an emotionally mature individual is one who enjoys good mental health and feels safe and is able to obtain what he wants in this life, unlike what happens with an immature emotional individual who has negative characteristics, including anxiety, fear, tension and others. 
International Journal of Childhood, Counselling, \& Special Education (CCSE), Volume2, Issue2, June: 2021, pp.67-84

8. The individual's ability to positively adapt to feelings of aggression: - It means the emotional mature individual when he is exposed to an aggressive situation and does not apply this aggression to the other individual, unlike the emotionally immature individual who attacks people and highlights aggression on them, just as a mature person is emotional when exposed $\mathrm{A}$ specific problem strives to find the most appropriate solutions to it, as well as suppressing his anger and is a source of energy also in order to reach the solution of problems, unlike the person who is emotionally immature. (Jeromemurray, 2004: p12).

\section{Previous Studies:}

First: Previous studies dealt with the variable susceptibility to empathy:

- Mahmoud's study (2004): Entitled: Achievement, Altruism Behavior and Susceptibility to Empathy among Outstanding Students and University Students: The study aimed to find out the relationship of achievement, altruistic behavior, and the susceptibility of empathy among the outstanding and not the most outstanding students of the university, as this was conducted on a sample of (200) male and female students with (100) males and (100) females, and the researchers used the study to collect data, the measure of sympathy ability, which is the phrase On situations and issues they are going through, which is a scale consisting of (58) items, and by using the correlation coefficient and the Pearson equation, where results were found that there are statistically significant differences between achievement and altruistic behavior and the susceptibility of sympathy among those who are outstanding and not excelling in the studies of the university students. (Mahmoud, 2004: 193-220).

- The Skovrank study (Yesko frank 2004): entitled: Quantitative analysis of the equilibrium of sympathy capacity among university students: The aim of this study is to know the quantitative analysis of the equilibrium of sympathy susceptibility and to know the differences in students 'grades and progress as a result of their participation in educational guidance programs with a sample of students participating in training and others who have graduated from counseling programs, and by using the correlation coefficient and the T-test, and the results revealed the existence of an interaction between the ability Empathy between the sexes. Females are higher than males in the level of sympathy capacity at graduation. Likewise, males 'scores have increased in the level of sympathy capacity at the end of the program compared to its beginning through training. (p187: 2004, Yesko frank,).

Second: Previous Studies of Emotional Maturity Variable:

- Al-Mousawi study (2013): Entitled: Emotional maturity and its relationship to some variables 
International Journal of Childhood, Counselling, \& Special Education (CCSE), Volume2, Issue2, June: 2021, pp.67-84

among middle school students in Iraq: The study aimed to know the emotional perfusion and its relationship to some variables among middle school students in Baghdad governorate, and the scale was applied to a sample of 480 middle school students and in four education directorates and was identified in Baghdad governorate in Karkh and Rusafa, in which the stratified random method was used. The equal level was applied to eight schools distributed in Baghdad equally according to the following variables (gender, grade, branch and general directorate) and after the data were statistically processed using different statistical means (the T-test for one sample and two independent samples) and by this, the researchers found individuals suffering from immaturity Irritable. (Al-Mousawi, 2013: 1-81)

- Landau (1998): The relationship between emotional maturity, intelligence and divergent thinking: The study aimed to find out the relationship between emotional maturity, intelligence and divergent thinking for distinguished students in middle school. This study was established in America. For the purpose of that, the researchers used three measures on a sample consisting of (221) students, and after processing the data statistically through the use of the Pearson correlation coefficient and analyzing Binary variance, the results found that students who are characterized by high crying are emotionally mature and have divergent thinking, unlike what happens with low thinking students who are emotionally immature and do not have divergent thinking. (Landau, 1998: p100).

\section{Field Study Procedures}

\section{Study Approach:}

The descriptive approach was adopted in the current study in order to know the strength and direction of the relationship between the variables (susceptibility to empathy and emotional maturity) and their relationship to self-confidence.

\section{Study Population:}

The population of this study consisted of students from Diyala University for study (morning and evening) and for both sexes (males and females) for the academic year (2019. 2020). The number of Diyala University students reached (17642) by (7741) males and (9901) females, where the percentage of males was ( $(43.87 \%)$ of the total community, while the percentage of females constituted $(6.13 \%)$ of the total community

\section{The Study Sample:}

The study sample was chosen by the random stratified method of equal distribution, from students of Diyala University for the study (morning and evening), and in order for the study to be objective, the sample must be truly representative of the original community, meaning that it bears all the characteristics of the studied community (Al-Nuaimi, 2014: 63), And the study sample reached (400) male and female students, who were 
International Journal of Childhood, Counselling, \& Special Education (CCSE), Volume2, Issue2, June: 2021, pp.67-84

chosen equally by (200) males and (200)

females from university students. Table

(1) shows that:

Table (1): The study sample is distributed according to the college and gender

\begin{tabular}{ccccc}
\hline Specialization & Colleges & Male & Female & Total \\
& College of Education for the & 50 & 50 & 100 \\
\hline Humanist & Humanities & & \\
& College of Islamic Sciences & 50 & 50 & 100 \\
Humanist & College of Education for Pure & 50 & 50 & 100 \\
Scientific & Sciences & 50 & 50 & 100 \\
${ } }$ & College of Sciences & 200 & 200 & 400 \\
\hline
\end{tabular}

\section{Study Tools:}

To achieve the objectives of the study, the researchers required the following:

1. Building a measure of empathy vulnerability

2. Building the Emotional Maturity Scale:

First: A Scale of Sympathy:

The researchers reviewed the literature and studies on the susceptibility of empathy and could not reach an appropriate measure for the community and sample of the study, and through that, the researchers built a scale of sympathy receptivity among students of Diyala University, according to the following steps:

Psychometric properties of the empathy scale:

\section{A - Scale Validity}

The researchers verified the validity of the (validity) paragraphs of the scale as follows:

\section{Apparent Honesty:}

The apparent validity of the scale was verified by presenting it to a group of arbitrators and specialists in educational and psychological sciences, and it was previously mentioned in the validity of the paragraphs.

\section{Validation of Construction:}

This type of truthfulness is known as a hypothetical formation, meaning that it forms the theoretical framework in the tests because it is at the beginning of its construction and that the effort that will come is concentrated from the stage of doubt for the test in the characteristic that it measures to the stage of certainty (Odeh, 1998: 384).

We note that this type of truthfulness reflects the degree of accuracy with which the tool can measure what it has been designed to measure, as Graham and Lill considered, and in addition to that truthfulness of children includes all kinds of truthfulness, where information can benefit from content truthfulness and associative truthfulness ( concurrent) and predictive as a tool for building validity (Al-Nuaimi, 2014: 232). The validity of the construction was verified by means of a factor analysis of the scale of sympathy susceptibility.

\section{B - Evidence:}

The scale stability factor was calculated as follows:

\section{How to re-test:}


International Journal of Childhood, Counselling, \& Special Education (CCSE), Volume2, Issue2, June: 2021, pp.67-84

The researchers distributed the scale to a random sample of (60) male and female students of (30) male and (30) female students from the College of Education for Pure Sciences from the research community, where the scale was applied to them. After two weeks passed, the test was repeated again on the same sample from the first test, after which the researchers calculated the Pearson correlation coefficient between the scores of the respondents in the first test and their scores in the second test, where the test reliability coefficient reached $(0,86)$, which is considered a good reliability coefficient (Lindauist, 1950: 57).

\section{Cronbach's Alpha Coefficient of Internal Consistency:}

"The idea of the Alpha Cronbach equation is represented by calculating the correlations between the scores of the sample members on all the paragraphs of the sympathy scale, and as the stability coefficient that has been found according to this method shows the performance of the individual in each paragraph, meaning the homogeneity between the scale paragraphs (Cronbach, 1951: 298) The researchers found this method after conducting the scale on a sample of (100) male and female students, where the value of the found stability factor was (0.83), which represents a good stability coefficient.

\section{Second: Emotional Maturity Scale:}

The researchers reviewed the literature and studies on emotional maturity and was unable to reach a suitable measure for the community and sample of the study. Therefore, it required building an emotional maturity scale for students at Diyala
University, according to the steps below:

Psychometric properties of the Emotional Maturity Scale:

\section{A - Validity of the scale:}

\section{Apparent Honesty:}

This type of honesty depends primarily on the suitability of the scale to what it measures, as this appears through the clarity of the scale's paragraphs as well as the extent of their relationship to the characteristic that they measure, as some of that are decided by a number of arbitrators, and as the apparent honesty is an important indicator to prove other types of truthfulness Before it was used to measure differences between individuals (Robert, 1980: 442), this type of validity was verified by presenting the scale to a group of referees and specialists in educational and psychological sciences, and as previously mentioned in the validity of the paragraphs.

\section{Validation of Construction:}

This type of truthfulness is known as the hypothetical formation, meaning that it forms the theoretical framework in the tests because it is at the beginning of its construction and that the effort that will come is concentrated from the stage of doubt for the test in the characteristic that it measures to the stage of certainty (Odeh, 1998: 384).

We note that this type of truthfulness reflects the degree of accuracy with which the tool can measure what was put to measure it, Graham and Lilly (1984), in addition to that the validity of the construction includes all kinds of truthfulness, where it can benefit from the information on the veracity of the content (Content) 
International Journal of Childhood, Counselling, \& Special Education (CCSE), Volume2, Issue2, June: 2021, pp.67-84

and the associated honesty ( concurrent) and predictive as a tool for building validity (Al-Nuaimi, 2014: 232). The validity of the construction was verified by means of a factor analysis of the emotional maturity scale.

\section{B - Evidence:}

\section{Method of Retesting:}

The researchers distributed the scale to a random sample of (60) male and female students of (30) male and (30) female students from the College of Education for Pure Sciences from the research community, where the scale was applied to them. After two weeks passed, the test was repeated again on the same sample from the first test, after which the Pearson correlation coefficient was calculated between the scores of the respondents in the first test, and their scores in the second test, where the test reliability coefficient reached (0.84), which is considered a good reliability coefficient (Lindauist, 1950: 57).

\section{Cronbach's Alpha Coefficient of} Internal Consistency:

"The idea of the Cronbach alpha equation is represented by calculating the correlations between the scores of the individuals of the stability sample on all the paragraphs of the emotional maturity scale, and as the reliability coefficient that has been found according to this method shows the performance of the individual in each paragraph, in the sense of homogeneity between the scale paragraphs (Cronbach, 1951: 298). The researchers found this method after conducting the scale on a sample of (100) male and female students, where the value of the found stability factor was $(0,80)$, which represents a good reliability coefficient.

\section{Presenting and Discussing the Results of Study}

Presentation and Discussion of the Result of the First Hypothesis:

The hypothesis states: "University students have a statistically significant ability to empathize"

To verify this hypothesis, the arithmetic mean of the scores of the research sample was extracted on the scale of sympathy susceptibility, which reached $(66,9950)$ degrees, and with a standard deviation of $(10,00877)$. The hypothesis average reached (60) degrees, and to know the significance of the statistical differences between the arithmetic mean and the mean The hypothesis, the T-test was used for one sample, and the results showed that the calculated $\mathrm{T}$ value reached (13.978), which is greater than the tabular $\mathrm{T}$ value of (1.96), at a significance level (0.05) and a degree of freedom (399), and this indicates That the sample members have a tendency to sympathize, and Table (2) illustrates this:

Table (2): Results of the T-test for one sample of the study sample individuals on the scale of sympathy ability

\begin{tabular}{|c|c|c|c|c|c|c|c|c|}
\hline \multirow{2}{*}{$\begin{array}{l}\text { Sample } \\
\text { size }\end{array}$} & \multirow[t]{2}{*}{ Average } & \multirow{2}{*}{$\begin{array}{l}\text { Arithmetic } \\
\text { deviation }\end{array}$} & \multirow{2}{*}{$\begin{array}{l}\text { Hypothetical } \\
\text { mean }\end{array}$} & \multirow{2}{*}{$\begin{array}{l}\text { Degree } \\
\text { of } \\
\text { freedom }\end{array}$} & \multicolumn{2}{|c|}{ T-value } & \multirow{2}{*}{$\begin{array}{c}\text { Level of } \\
\text { significance }\end{array}$} & \multirow{2}{*}{$\begin{array}{c}\text { Significance } \\
\text { of the } \\
\text { difference }\end{array}$} \\
\hline & & & & & $\begin{array}{c}\text { The } \\
\text { standard }\end{array}$ & $\begin{array}{l}\text { Computed } \\
\text { tabular }\end{array}$ & & \\
\hline 400 & 66,9950 & 10,00877 & 60 & 399 & 13,978 & 1.96 & 0.05 & Significant \\
\hline
\end{tabular}


International Journal of Childhood, Counselling, \& Special Education (CCSE), Volume2, Issue2, June: 2021, pp.67-84

The researchers interpreted this result that university students had a positive trend towards the ability to sympathize, as it represents a common human willingness in society and that it appears through being affected by some of the situations that university students are exposed to, which differ from one society to another according to the customs and traditions inherited in it, in other words that individuals The sample has a tendency to sympathize, which indicates that the research sample has a high degree of emotion, which makes them influenced by others emotionally. Whereas, the more attached a person is to others, the more sympathetic he is, and vice versa, and thus attachment is considered one of the effective elements in terms of human influence, which occurs as a result of repeated situations with an emotional aspect, which makes the person delve into such topics so that we can demonstrate this through behavioral behavior. Resulting from the person, such as the appearance of (smiling, crying, looking, or moving) all of them bring the individual closer to the subject of sympathy and the formation of varying relationships that may be and through that we find that attachment is one of the most important things in the ability to sympathize, which is through help, love or respect, and from here we find That the capacity for empathy and attachment is affected by each of them in the other, in which a positive correlation was found, and that a person more amenable to sympathy is a person less attached, as well as the attachment was considered due to several reasons for education or the same person, and from which it is due to the current situation in the country that made the sample members go through difficult circumstances It affects all areas of their lives, which makes sympathy present among them in order to help each other in order to feel love, happiness, security and hope, (Shehatha and Al-Asimi, 2016: 188189).

\section{Presentation and Discussion of the Result of the Second Hypothesis:}

The hypothesis states the following: "There are no statistically significant differences in the susceptibility of empathy among university students according to the gender variable (male female)."

To find out the statistically significant differences in the variable susceptibility to empathy according to the gender variable (male-female), the $\mathrm{T}$ test was used for two independent samples, as the arithmetic mean of males reached $(65,6200)$ degrees with a standard deviation of $(12,03327)$ degrees, while the arithmetic mean of females was It reached $(68,3700)$ degrees with a standard deviation of $(7,22872)$ degrees, and the calculated $\mathrm{T}$ value reached $(2,770)$ degrees, which is greater than the tabular $\mathrm{T}$ value of (1.96) with a level of significance (0.05), and a degree of freedom (398) This result indicates that there are statistically significant differences in the variable susceptibility to empathy depending on the variable of sex and in favor of females, and Table (3) illustrates that: 
International Journal of Childhood, Counselling, \& Special Education (CCSE), Volume2, Issue2, June: 2021, pp.67-84

Table (3): The results of the T-test for two independent samples on the scale of sympathy susceptibility according to the gender variable (male - female)

\begin{tabular}{|c|c|c|c|c|c|c|c|}
\hline \multirow[t]{2}{*}{ Gender } & \multirow{2}{*}{$\begin{array}{l}\text { Sample } \\
\text { size }\end{array}$} & \multirow[t]{2}{*}{ Average } & \multirow{2}{*}{$\begin{array}{l}\text { Standard } \\
\text { deviation }\end{array}$} & \multicolumn{2}{|c|}{ T-value } & \multirow{2}{*}{$\begin{array}{c}\text { Level of } \\
\text { Significance }\end{array}$} & \multirow{2}{*}{$\begin{array}{l}\text { Significance of } \\
\text { the Difference }\end{array}$} \\
\hline & & & & $\begin{array}{c}\text { The } \\
\text { standard }\end{array}$ & $\begin{array}{l}\text { Computed } \\
\text { tabular }\end{array}$ & & \\
\hline Male & 200 & 65,6200 & 12,03327 & 2,770 & 1.96 & 0.05 & Statistically \\
\hline Female & $\underline{200}$ & 68,3700 & 7,22872 & & & & $\begin{array}{l}\text { Significant } \\
\text { For the } \\
\text { Benefit of } \\
\text { Female }\end{array}$ \\
\hline
\end{tabular}

This result confirmed the existence of statistically significant differences in the variable susceptibility to empathy according to the variable of gender and in favor of females. The researchers interpreted this result as that girls have higher empathy susceptibility than males where the emotional aspect is always present and I am the basis for making different decisions in Their lives due to biological preparations, social upbringing, community culture, ethical standards, what we expect from roles and response to emotional demands, all of this has a great impact because the girl is affected by everything around her, as the capacity for empathy is associated with the support of females more than males and therefore, females have more sympathy capacity than males And the best female fans are their mothers due to their having the same positive social and emotional tendencies higher than their awareness of being encouraged by the fathers and there are many studies that have confirmed this as studies (Eisenberg \& Leno, 1983, Kalliopouska, 1984, Barnett \& Thomposon, 1985, Eisenberg et al, 1988) according to what has been done. Remind him with psychology that the child in the first years of the child's life that is before entering school belongs to the gender to which he belongs and takes an approximation A: All the traits are through imitation of that character and its attributes since mothers are more affectionate than fathers and this is what the study (Kallipouska, 1984) indicated, and this is one of the reasons that indicate the presence of more sympathy among girls, given that females are the best people who express their feelings when they see them To others because they are better than males at reading verbal emotional stimuli than the corresponding individual and also consider him more sympathetic to social situations.

\section{Presentation and Discussion of the result of the Third Hypothesis:}

It states: "University students are characterized by emotional maturity."

To achieve this goal, the arithmetic mean of the scores of the research sample was extracted on the emotional maturity scale, which reached $(64,9500)$ degrees, with a standard deviation of $(9,33157)$ degrees, and the hypothetical average reached (60) degrees, and to know the significance of the statistical differences between the arithmetic mean and the mean The hypothesis, the T-test was used for one sample, and the results showed that the calculated $\mathrm{T}$ value reached $(10,609)$, which is greater than the tabular $\mathrm{T}$ value of (1.96), at a 
International Journal of Childhood, Counselling, \& Special Education (CCSE), Volume2, Issue2, June: 2021, pp.67-84

level of significance $(0.05)$ and a degree emotional maturity, and Table (4) of freedom (399), and this indicates illustrates this:

That the sample members have

Table (4): Results of the T-test for one sample of the individuals of the research sample on the emotional maturity scale

\begin{tabular}{|c|c|c|c|c|c|c|c|c|}
\hline \multirow{2}{*}{$\begin{array}{l}\text { Sample } \\
\text { size }\end{array}$} & \multirow[t]{2}{*}{ Average } & \multirow{2}{*}{$\begin{array}{l}\text { Arithmetic } \\
\text { deviation }\end{array}$} & \multirow{2}{*}{$\begin{array}{c}\text { Hypothetical } \\
\text { mean }\end{array}$} & \multirow{2}{*}{$\begin{array}{l}\text { Degree } \\
\text { of } \\
\text { freedom }\end{array}$} & \multicolumn{2}{|c|}{ T-value } & \multirow{2}{*}{$\begin{array}{c}\text { Level of } \\
\text { significance }\end{array}$} & \multirow{2}{*}{$\begin{array}{l}\text { Significance } \\
\text { of the } \\
\text { difference }\end{array}$} \\
\hline & & & & & $\begin{array}{c}\text { The } \\
\text { standard }\end{array}$ & $\begin{array}{l}\text { Computed } \\
\text { tabular }\end{array}$ & & \\
\hline 400 & 9,33157 & 9,77693 & 60 & 399 & 609.10 & 1.96 & 0.05 & Significant \\
\hline
\end{tabular}

The researchers interpreted this result by observing a high degree of emotional maturity among university students, and this result was in agreement with the study (Al-Ashwal, 1982) and the study (Muhammad, 2010), and to clarify this that university students by virtue of their knowledge and experience that were acquired through attitudes The life they were exposed to during the university stage, as it made them deal with all the emotional situations and problems they encounter, whether inside or outside the university without any emotion, and this indicates that they have reached the highest degree of emotion, and this indicates that they are emotionally mature (Azza Et al., 1999: 95), and with this that the researchers' conclusion is consistent with the naturalism of Cattell's theory on which he built the scale through one of Cattell's sixteen features, which is the trait of emotional maturity, as this feature is among the sixteen characteristics that must be The university student is distinguished by it, in addition to his sixteen characteristic of Cattell, as well as the encouragement by parents to adopt acceptable actions and responses who suffer as a kind of adversity, and Cattle also considered that the power of the $\mathrm{I}$ is the fundamental stone in the personality of the individual which was expressed by Catel. This feature is emotional maturity, where it was found that the one who can control emotional situations and problems has the ability to emotional stability and thus, he is emotionally mature. Otherwise, he is an emotionally immature person in whom the strength of I is on a low degree and who was found to be an oversight for him drowning in emotion in the face of life. Thus, his actions do not correspond to the facts of the situation. (Abu Zeid, 1987: 185)

As emotionally mature persons know, they are the ones who have reached the highest degree of emotion, as their emotions are not easily aroused, unlike emotionally immature persons who are negligent to stimulate their emotions towards the situations they are exposed to. (Yunus, 2004: 257).

Presentation and Discussion of the Result of the Fourth Hypothesis:

It states: "There is no statistically significant relationship between the variables of the susceptibility of empathy and emotional maturity among university students:

To achieve this goal, the Pearson correlation coefficient was calculated, between the total score of the research sample on the scale of empathy ability, 
International Journal of Childhood, Counselling, \& Special Education (CCSE), Volume2, Issue2, June: 2021, pp.67-84

and the total score on the emotional maturity scale, where the value of the correlation coefficient was $(0.780)$ degrees, and to test the significance of the correlation coefficient, the T-test for the significance of the correlation coefficient was used, and the results showed That the calculated $\mathrm{T}$ value of the significance of the correlation coefficient is equal to (22.55) degrees and it is greater than the tabular $T$ value of (1.96) degrees at the level of significance $(0.05)$ and the degree of freedom (398), and this indicates that there is a positive direct correlation relationship. Between the two variables susceptibility to empathy and emotional maturity, Table (5) illustrates this:

Table (5): The value of the Pearson correlation coefficient and the T value for the indication of the correlation coefficient of the relationship the association between the ability of empathy and emotional maturity

\begin{tabular}{lccccc}
\hline Variables & $\begin{array}{l}\text { Correlation } \\
\text { coefficient value }\end{array}$ & \multicolumn{2}{l}{$\begin{array}{l}\text { The T-value of the correlation } \\
\text { coefficient } \\
\text { Calculated }\end{array}$} & $\begin{array}{l}\text { Tabular } \\
\text { Significance of the } \\
\text { relationship at } 0.05\end{array}$ \\
$\begin{array}{l}\text { The ability of } \\
\text { empathy } \\
\text { Emotional maturity }\end{array}$ & 0,780 & 24,866 & 1.96 & $\begin{array}{l}\text { A positive, positive, } \\
\text { statistically significant } \\
\text { relationship }\end{array}$ \\
\hline
\end{tabular}

Through this result of the study, he sees that there is a positive relationship between the susceptibility to empathy and emotional maturity, as it was found that people who possess the susceptibility to empathy are emotionally mature because emotions are part of the emotions, so people who have the susceptibility to empathy have reached the highest degree of maturity The emotional, especially at this stage, which is the university level, where they are able to control their emotions towards any emotional situation or problems they face because they are more stable and balanced and can face them without emotion and the ability to sympathize is represented by the emotions that are part of these emotions where the person feels or feels the problems or the person The interviewer is through understanding their thoughts and feelings and on the basis of that his task is to approach him and try to help him in order to solve his problem that he suffers from, and that the people who have sympathy have the characteristic of emotional maturity and this characteristic of emotional maturity is exemplified by his ability to control all the emotions and emotions that may be encountered in His life, whether he entered the university or outside it, or in the field of his profession, when he intends to help others, as a mature person can He deals with these problems that others may face with emotional consistency, which are represented by emotional and emotional problems because a person can feel others and understand their thoughts because he has the capacity for sympathy that feels what they are suffering from and tries as much as possible to help them that the capacity for empathy is not complete if the individual is not emotionally mature because both of them $\mathrm{He}$ is dependent on the other when helping others or when he may be exposed to such situations and how to deal with them. 
International Journal of Childhood, Counselling, \& Special Education (CCSE), Volume2, Issue2, June: 2021, pp.67-84

\section{Conclusion of study}

\section{First: The Results of Study:}

The study reached several results, which can be summarized as follows:

1. The university students have the ability to empathize at a higher rate than the average of the society they are associated with, and compared to the hypothetical average of the scale of sympathy ability.

2. The university students possess emotional maturity at a higher rate than the average of the society to which they are related and in comparison, with the hypothetical average of the Emotional Maturity Scale.

3. Females surpass males in their enjoyment of a high degree of emotional maturity.

4. There are statistically significant differences in the variable susceptibility to empathy according to the gender variable and in favor of females.

5. The relationship between the susceptibility of empathy and emotional maturity was statistically significant, because the calculated $\mathrm{T}$ value is higher than the tabular value, and this means that there is a relationship between the susceptibility of empathy (the independent variable) and emotional maturity (the dependent variable), and just as it is related to (emotional maturity).

Second: Recommendations of Study:

Through the findings of the study in the study, the study recommended the following:

1. Benefiting from current research by educational advisors.
2. Researchers in the field of psychology have benefited from the measure of the susceptibility of empathy in order to diagnose the susceptibility of empathy.

3. The educational institutions and subordinate counseling units, whether at the university or schools, to present a lecture in which emotional maturity is defined as representing the ability of the individual to control and control his emotions, whether from situations or by others.

\section{Third: Study Suggestions:}

As a continuation of the current study, the study presents the following proposals:

1. A study of the capacity for empathy in daily life and society in the circles of Iraqi society.

2. The effectiveness of a counseling program to develop the capacity for empathy among secondary school students.

3. The emotional maturity of state employees of all kinds and positions considering some variables.

\section{References}

Al-Bayoumi, Saad Riyadh (2019). Intellectual stagnation and emotional equilibrium among a sample of students from Taif University (Saudi Arabia). Journal of Psychological and Educational Sciences, 3(32).

Al-Faramawy, Hamdi (2001). The Pillars of Psychological Construction, an analytical, explanatory and directive study in human behavior, 1st Edition, Cairo, ATRAC for printing, publishing and distribution. 
International Journal of Childhood, Counselling, \& Special Education (CCSE), Volume2, Issue2, June: 2021, pp.67-84

Al-Issawi, Abd al-Rahman Muhammad (2002). Encyclopedia of Modern Psychology, Volume Three, Beirut, University Knowledge House, Cairo.

Al-Mousawi, Shatha Khalil Khamis (2013). Emotional maturity and its relationship to some variables among middle school students in Baghdad governorate. a master's thesis, the Arab Higher Institute, Baghdad.

Al-Obaidi, Afra Ibrahim Khalil (2011). The Nature of the Relationship between Empathy and Aggressive Behavior. Damascus University Journal for Psychological and Educational Research, 27(3):133-231.

Al-Rashdi, Bashir Saleh, \& Al-Sahl, Rashid Ali (2000). Introduction to Psychological Counseling. 1st Edition, AlFalah Library for Publishing and Distribution, Kuwait.

Abd al-Salam, Samia, Abd al-Rahman (1992). Moral Values, A Critical Study of Islamic Thought and Contemporary Thought, 1st Edition, Cairo, The Egyptian Renaissance Library.

Beck, Aaron (2000). Cognitive therapy and emotional disturbances. Translation: Adel Mustafa - Ghassan Yaqoub. Beirut: Dar Al-Nahda.

Cattall, stager, R (1961). psychology of personality. new york.m (Gorw Hill) co (3rd.ed).

Dewa, Makki Babiker Saeed \& AlSiddiq, Muhammad Al-Tayeb (2019). The role of religious courses in achieving emotional balance and enhancing social responsibility among students of the Islamic Studies departments in Sudanese universities.
The Arab Islamic Journal of Studies and Legitimacy, College of Education. Hantoub. University of Gezira, Sudan, (7).

Dymond, R, F (1949). A scale for the measurement of Empathy ability. Journal of consulting psychogy.

Hoffman, M. (1982). The measurement of empathy, In C. Izard (ed.) Measuring emotions in infants and children. Cambridge Cambridge University press.

Hoffman, M. L. (1977). Sex differences in empathy and related behaviors. Psychological Bulletin, 84(4):712-722, https://doi.org/10.1037/0033-

2909.84.4.712.

Hoffman, M (1978). Development of Affect. New York, plenum press.

Hoffman, M. L. (2000). Empathy and moral development. Implications for caring and justice Cambridge. University Press. 5-Halahan.

Jerome murray (2004). are you gruwin up or just getting older? an internet article under the title emotional maturity with modifications.

Katz. R. (1963). Empathy. Its nature and Uses, New York

kazdin, A, E, (2000). Encyciopedia ofpsychology. ApA, oxford university press, vol.7.p528

Landau, m (1998). The self_the Globan factor of Emotional maturity. Roeper Review, 20 (3): $174-178$, https://doi.org/10.1080/0278319980955 3886.

Mahmoud, he is the hand of Hanafi, Faraj, Muhammad Anwar Ibrahim 
International Journal of Childhood, Counselling, \& Special Education (CCSE), Volume2, Issue2, June: 2021, pp.67-84

(2004). Achievement, altruistic behavior, and sympathy among the outstanding and not the most outstanding students of the university. House of the System, 21(66).

Yesko, frank m (2004). Assessment of differences in the balanced emotional empathy among beginning practicum and gradations students in counselor education program cumber library tilte page for etd.

Yunus, Muhammad Bani (2004). Principles of Psychology. Dar Al-Shorouk for Publishing and Distribution, Amman, Jordan. 